Acta Technologica Agriculturae 3

Nitra, Slovaca Universitas Agriculturae Nitriae, 2019, pp. 70-74

\title{
CHARACTERIZATION OF TABLETS MADE FROM MIXTURE OF CHARRED AGRICULTURAL RESIDUES WITH AND WITHOUT EMBEDDED FERTILIZER
}

\author{
Yit Leng LEE ${ }^{1,2 *}$, Osumanu Haruna AHMED ${ }^{2,3}$, Samsuri Abdul WAHID ${ }^{3}$, Zakry Fitri AB AZIZ \\ ${ }^{1}$ Universiti Malaysia Perlis, Kampus Uniciti Alam, Padang Besar, Perlis, Malaysia \\ ${ }^{2}$ Universiti Putra Malaysia Bintulu Campus, Bintulu, Sarawak, Malaysia \\ ${ }^{3}$ Universiti Putra Malaysia, Serdang, Selangor, Malaysia
}

\begin{abstract}
Densification of biochar can reduce transportation and handling costs, as well as significantly decrease loss of biochar during soil application. Although the nutrient-rich biochar tablets may be a potential cost-effective slow-release fertilizer in soil, there is a lack of information on characterization of mixtures of rubber tree twigs and rice residues tablets with embedded NPK fertilizer. Objective of this work was to determine the physical and chemical properties of biochar tablets with and without embedded fertilizer. Biochar tablets were produced by blending of charred rice husk, rice straw, rubber tree twigs, and starch and followed by tableting. Their production with embedded fertilizer was similar to production process of tablets without it, except adding the NPK fertilizer to blending phase prior to tableting. Fourier-transform infrared spectra analysis indicates was utilized for determination of presence of ammonium and phosphorus substances in the biochar tablets with embedded fertilizer (BFs). The NPK fertilizer significantly increased tablet density and total contents of nitrogen, phosphorus, potassium, calcium and magnesium. The presence of higher amount of nutrients in BFs suggests that it could release nutrients for plant use.
\end{abstract}

Keywords: biochar; carbon; nutrient; rice husk; rubber tree twigs

Malaysia is one of the world top producers of natural rubber (Department of Statistics Malaysia, 2016). Oil palm and rubber dominate the agricultural land utilization in Malaysia; rice is in the third place. Rice cultivation covers an area of nearly 209,300 ha (Karim et al., 2004). Approximately 4 million tons of rice straw had been produced by 2015 and 0.48 million tons of rice husk is produced annually in Malaysia (Shafie et al., 2014).

Rubber tree twigs and rice residues generated from rubber pruning and rice production are commonly left to decompose on the ground or burned in the field with consequent negative impact on the environment (Rondon et al., 2007). These agricultural residues represent the lowcost renewable resources, which should be reused and valorised. An alternative to agricultural residue management is thermal conversion of rice residues and rubber tree twigs to biochar, while simultaneously generating the energy during heating (Dhaundiyal and Hanon, 2018). Biochar can be utilized as an efficient long-term $C$ sink in terrestrial systems for mitigation of climate changes. Moreover, it is a suitable soil amendment as it increases water and nutrient retention (Vaughn et al., 2013). Nevertheless, the brittle and low density biochar hinder the process of storage, transportation, and even soil application. Husk and Major (2008) reported that $25 \%$ of biochar applied was lost during the field application. Approximately $20-53 \%$ of biochar incorporated into soil was also lost by surface runoff during heavy precipitation events (Major et al., 2010). High amount of ash is also produced during the biochar production process (Dróżdż et al., 2016). Densification of biochar is one of the potential ways to decrease the high costs associated with transport and application rates during soil application, as it is challenging to handle the light density of biochar.

The addition of lignocellulosic biomass-derived biochar into the soil complements mineral fertilizers, increasing crop yield. Several researchers have suggested that supplementing of biochar with NPK fertilizer and bentonite clay boosted rice yields by $15-30 \%$ compared to chemical fertilizers applied at a rate of $500 \mathrm{~kg} \cdot \mathrm{ha}^{-1}$ (Joseph et al., 2013; Qian et al., 2014). This could minimize the chemical inputs and the polluting effect of overutilization. BFs will have lesser amounts of voids and higher density, facilitating its handling. Although the nutrient-rich biochar tablets are suggested to be better than conventional fertilizer in terms of supplying the plant nutrition demand throughout the specific plant's lifespan, there is lack of information on characterization of mixtures of rubber twigs and rice tablets embedded with NPK fertilizer. In presented study, biochar derived from thermal decomposition of rice straw, rice husk and rubber tree twigs was blended with commercial fertilizer and subsequently densified into tablets. The physio-chemical properties of biochar tablets with and without embedded fertilizer were investigated for the assessment of being an environmentally friendly slow-release fertilizer.

Contact address: Yit Leng Lee, 1. Department of Mechanical Engineering Technology, Faculty of Engineering Technology, Universiti Malaysia Perlis, Kampus Uniciti Alam, Padang Besar, 02100 Perlis, Malaysia. 2. Department of Crop Science, Faculty of Agriculture and Food Sciences, Universiti Putra Malaysia Bintulu Campus, 97008 Bintulu, Sarawak, Malaysia, e-mail: yllee@unimap.edu.my 


\section{Material and methods}

\section{Sample collection and preparation}

Rubber tree twigs and rice residues were collected from a rubber plantation and a paddy field in Perlis (located at $6.4449^{\circ} \mathrm{N}, 100.2048^{\circ} \mathrm{E}$ ). The samples were sun-dried for 3 days. Rubber tree twigs were chopped into $2 \mathrm{~cm}$ sections using a SIMA Model RC61605 wood chipper (with a capacity of 2,000-4,000 kg.hr ${ }^{-1}$, China). The rice straws were cut into pieces $15 \mathrm{~cm}$ long and kept in a gunny sack, whereas the rice husks were ground and sieved into size of $1 \mathrm{~mm}$ and kept in a sealed container. The rubber tree twigs, rice straws and rice husks were charred separately prior to the production of the biochar tablets.

\section{Biochar production and preparation}

Biochar was produced using a stainless-steel kiln fabricated locally at the Department of Mechanical Engineering Technology, Universiti Malaysia Perlis, Perlis, Malaysia. The temperature was measured using Lutron Model TM969 handheld infrared thermometer (measurement up to $1,000{ }^{\circ} \mathrm{C}$, adjustable emissivity value from 0.1 to 1.00 ) every 30 minutes during the combustion. During the charring, a maximum temperature of $500{ }^{\circ} \mathrm{C}$ was attained after 1 hour of ignition. The average temperature of the kiln throughout the charring process was approx. $340{ }^{\circ} \mathrm{C}$. The charring process was completed in 3 hours, after which the charred product was collected and weighed to determine the percentage yield of the charring process. The result indicates that the percentage yield was approx. $34 \%$. The charred materials were ground and sieved to pass a $1 \mathrm{~mm}$ sieve prior to their blending with and without fertilizer.

\section{Biochar tablet (BT) production}

The biochar tablets (BTs) consisted of $50 \%$ charred rice husk, $30 \%$ charred rice straw and $20 \%$ charred rubber twigs. Subsequently, biochar was blended with $20 \mathrm{wt} . \%$ of starch and 30 wt.\% of water as a binder using a mixer. Thereafter, the mixture was heated at $100^{\circ} \mathrm{C}$ for 5 minutes using a water bath. Afterwards, the biochar mixture was densified using a single press tablet with punch weight of $0.4 \mathrm{t}$. Tablets with dimensions of $6 \mathrm{~mm}$ in height and $10 \mathrm{~mm}$ in diameter were generated. BTs were oven dried at $60{ }^{\circ} \mathrm{C}$ for 1 hour. After oven-drying, the biochar tablets were cooled and kept in air-tight container.

\section{Biochar tablets with embedded fertilizer (BFs) production}

Biochar derived from rice straw, rice husk and rubber tree twigs was blended with 20 wt.\% of starch and $30 \mathrm{wt} . \%$ of water as binder using a mixer. The mixture was then heated at $100{ }^{\circ} \mathrm{C}$ for 5 minutes using water bath. Subsequently, $5: 3: 3$ NPK fertilizer was mixed into the biochar. The sources of NPK fertilizer were ammonium sulphate, triple superphosphate, and muriate of potash, respectively. The mixture ratio of fertilizer to biochar was $1: 2$. The mixture was densified using a single press tablet. The biochar tablets embedded with fertilizer (BFs) were then dried at $60{ }^{\circ} \mathrm{C}$ for
1 hour in the oven. After oven-drying, BFs were left to cool down and stored in an air-tight container.

\section{Physical properties test}

\section{Unit density and tablet durability}

The unit density of the BTs and BFs was measured by weighing the individual tablets and calculating their volume based on their length and diameter as per the following equation (Eq. 1):

$$
\rho=\frac{m}{V}
$$

where:

$\rho \quad-$ density of individual tablet $\left(\mathrm{g} \cdot \mathrm{cm}^{-3}\right)$

$m \quad$ - weight of individual tablet $(\mathrm{g})$

$V \quad$ - volume of individual tablet $\left(\mathrm{cm}^{3}\right)$

Tablet durability was measured by weight loss upon vibration. Initial weight of both the BTs and BFs was recorded. Afterwards, tablet durability was tested using a vibrating screen size $4 \mathrm{~mm}$ sieve. After 10 minutes, they were weighed again and the final weights were recorded. The tablet durability was calculated using the following equation (Eq. 2):

$$
P d=100-\left(\frac{m i-m f}{m i}\right) \times 100 \%
$$

where:

$$
\begin{aligned}
& P d \quad \text { - tablet durability }(\%) \\
& m i \quad-\text { initial weight of samples }(\mathrm{g}) \\
& m f \quad-\text { final weight of the samples }(\mathrm{g})
\end{aligned}
$$

\section{Chemical properties test}

\section{$\mathrm{pH}$ and electrical conductivity}

By mixing the sample with deionized water at a $1: 10$ ratio for 24 hours, the $\mathrm{pH}$ and electrical conductivity (EC) of BTs and BFs were determined using Sartorius Model PB10 pH meter (measuring $\mathrm{pH}$ range: 0-14; accuracy: \pm 0.01 ) and Model EC3000 conductivity meter (measuring range: 0-200 mS; accuracy: $\pm 2 \%$ ) respectively.

\section{Total macronutrient}

Dry ashing was adopted for the content determination of phosphorus ( $\mathrm{P}$ ), potassium (K), calcium (Ca) and magnesium (Mg). Approx. $1 \mathrm{~g}$ of sample was weighed into crucible and then initially ashed at $300{ }^{\circ} \mathrm{C}$ for 1 hour in a DAIHAN model FHP03 muffle furnace (WiseTherm, Korea, resolution: $1{ }^{\circ} \mathrm{C}$, $1 \mathrm{~min})$. Later, the temperature was increased to $500{ }^{\circ} \mathrm{C}$ and maintained until the samples became grayish in colour. Afterwards, the samples were left to cool down. Few drops of distilled water were added to the samples, followed by $2 \mathrm{ml}$ concentrated hydrochloric acid $(\mathrm{HCl})$. Samples were evaporated to dryness on a hot plate. A $10 \mathrm{ml}$ of $20 \%$ nitric acid $\left(\mathrm{HNO}_{3}\right)$ was added to the samples and placed in a water bath for 1 hour. Subsequently, samples were filtered through Whatman no. 2 filter paper into volumetric flask of $100 \mathrm{ml}$ and diluted to this volume. 


\section{Total carbon and nitrogen analysis}

Total carbon (TC) and total nitrogen (TN) of the BTs and BFs were determined using a LECO model TruMac CNS analyzer (LECO Corporation, USA).

\section{Fourier transform infrared spectra (FTIR) analysis}

The BTs and BFs were analysed using the Perkin-Elmer FTIR Spectrometer Spectrum 2000 (measuring range: $7,800-400 \mathrm{~cm}^{-1}$, resolution: starting with $0.5 \mathrm{~cm}^{-1}$ ) with a Perkin-Elmer Universal Attenuated Total Reflectance (ATR) sampling accessory to obtain their FTIR spectra. Data collection and processing were performed by Spectrum version 6.2.0.0055 software (Leng et al., 2011).

\section{Statistical analysis}

Pair-samples T-test was used to detect significant differences in the chemical and physical properties between BTs and BFs. Statistical Analysis System (SAS) software version 9.2 was used for the statistical analysis.

\section{Results and discussion}

Unit density, tablet durability and moisture content

Density is a fundamental physical property which controls the movement and interaction of biochar in the soil. Low density $\left(0.25-0.3 \mathrm{~g} \cdot \mathrm{cm}^{-3}\right)$ has been reported for soft wood biochar (Brewer et al., 2014). This density makes it challenging for biochar to be handled and transported. Furthermore, significant amount of biochar with such density is lost during soil application (Husk and Major, 2008). Unit density of BFs $\left(0.90 \mathrm{~g} \cdot \mathrm{cm}^{-3}\right)$ was significantly higher than that of BTs $\left(0.70 \mathrm{~g} \cdot \mathrm{cm}^{-3}\right)$. This difference could be attributed to the pores being filled with the NPK fertilizer (BFs), resulting in the density increase of BFs. The densities of BTs and BFs were higher than that of softwood biochar reported by Brewer et al. (2014). This indicates that tableting enables binding and compressing of the biochar particles to increase the densities of BTs and BFs.

Handling, transporting and storing of biochar are influenced by its durability (Weber and Quicker, 2018; Macák et al., 2015). The tablet durability of BTs and BFs fall in the range of high durability reported by Adapa et al. (2003).
Higher durability of BTs and BFs indicates that they do not easily crack and the mass loss during their transportation can be reduced.

\section{$\mathrm{pH}, \mathrm{EC}$, total content of phosphorus, potassium, calcium, and magnesium}

Biochar has a significant impact on the physicochemical processes in soils that may influence the microbial communities and this aspect strongly depends on the soil $\mathrm{pH}$ (Sheng et al., 2016). The alkalinity of biochar increases the soil $\mathrm{pH}$ with a simultaneous increase in growth of soil microorganism, as well as bioavailability of soil organic carbon (Sheng and Zhu, 2018). The BT showed a high pH (9.34) and this finding was similar with the $\mathrm{pH}$ of biochar obtained by Leng et al. (2011), who also studied biochar production by combustion at low temperature and long residence time. On the contrary, fertilizer addition to biochar tablets significantly decreased the $\mathrm{pH}$ value to 5.92 (Table 1). When the charred rice residues and rubber tree twigs were mixed with ammonium sulphate, the dissociation of protons from oxygenated functional groups of biochar surfaces and ammonium sulphate released free hydrogen ions (Xue et al., 2017; Singh et al., 2017). Sulphuric acid was generated after the binding reactions of free hydrogen ions and sulphate ions, thereby reducing the $\mathrm{pH}$ of the BFs.

Electrical conductivity (EC) is a predominant factor for controlling seed germination and plant growth (Andreasen et al., 2014). The EC of biochar greatly depends on the combustion conditions and the biomass type used to produce it (Mandal et al., 2018). The EC value of BTs was $3.78 \mathrm{~ms} \cdot \mathrm{cm}^{-1}$ and it was in the range of biochar EC value reported by Limvikran et al. (2018). A significantly higher value of EC of BFs $\left(41.16 \mathrm{~ms} \cdot \mathrm{cm}^{-1}\right)$ can be attributed to the deposit of mineral salts thanks to addition of NPK fertilizer. Blending of fertilizer with the BFs led to significantly higher concentration of total phosphorus, potassium, and calcium (Table 1). It is essential for the BFs to contain ample amounts of essential plant nutrients, which could substitute or supplement conventional fertilizers. Total content of magnesium in BTs $(0.20 \%)$ was significantly higher than in BFs $(0.17 \%)$. It appears that embedding with fertilizer led to lower magnesium content in the BFs. Increase in potassium and calcium content in the BFs might have caused competition with the magnesium in terms of binding with

Table $1 \mathrm{pH}$, electrical conductivity (EC), total content of phosphorus, potassium, calcium, and magnesium of tablets produced from charred rice residues-rubber tree twigs mixture embedded with (BFs) and without fertilizer (BTs)

\begin{tabular}{|l|c|c|}
\hline \multirow{2}{*}{ Element } & \multicolumn{2}{|c|}{ Types of biochar tablets } \\
\hline pH & without fertilizer (BTs) & with fertilizer (BFs) \\
\hline EC $\left(\mathbf{m s} \cdot \mathbf{c m}^{-\mathbf{1}}\right)$ & $9.34^{* \mathrm{a}} \pm 0.01$ & $5.92^{\mathrm{b}} \pm 0.02$ \\
\hline Phosphorus (\%) & $3.78^{\mathrm{b}} \pm 0.04$ & $41.16^{\mathrm{a}} \pm 0.76$ \\
\hline Potassium (\%) & $0.07^{\mathrm{b}} \pm 0.01$ & $0.36^{\mathrm{a}} \pm 0.01$ \\
\hline Calcium (\%) & $1.23^{\mathrm{b}} \pm 0.09$ & $2.45^{\mathrm{a}} \pm 0.06$ \\
\hline Magnesium (\%) & $0.73^{\mathrm{b}} \pm 0.06$ & $1.09^{\mathrm{a}} \pm 0.04$ \\
\hline
\end{tabular}

* - means $(n=3)$ within a row with the same letter indicate no significant difference between the treatment means at $\alpha=0.05$ 
the negative biochar surface charge. The magnesium most probably precipitated with the phosphate and ammonium, formed magnesium ammonium phosphate, which was easier to decompose thermally during the tableting processing (Chen et al., 2015).

\section{Total content of carbon and nitrogen}

Total content of C in BTs (48.49\%) was lower than the $C$ content in biochar reported in literature (Yi et al., 2016; Gonzaga et al., 2017). This could be caused by higher amount of ash in the rice husk, resulting in a lower total C concentration in the BTs. This is consistent with the observation made by Claosten et al. (2014), who also discovered that the lower $\mathrm{C}$ content of rice husk (38.10\%) was because rice husk is composed of much higher amount of ash in contrast to other agricultural residues. In comparison to $C$ content of BTs, the reduced $C$ content in BFs (32.35\%) is related to the added mineral salt embedded in the tablet with fertilizer. This agrees with Dunnigan et al. (2018), who also observed that high mineral salt content reduced the $\mathrm{C}$ content in rice husk-derived biochar.

Total $N$ content $(0.75 \%)$ in BTs was comparable to the reported $N$ content of rice husk biochar produced at low temperature (Yi et al., 2015; O'Connor et al., 2018). The blending of ammonium sulphate fertilizer with the BFs significantly increased the concentration of total $N$ content (4.96\%). Nitrogen is an important element required for successful plant growth, development, and reproduction. Application of BFs can result in increase in the plants' absorption of inorganic nitrogen compared to the BTs.

\section{FTIR Analysis}

Fig. 1 shows the bands present in the spectra of tablets made of charred rice residues-rubber tree twigs mixture embedded with (BFs) and without fertilizer (BTs). As expected, significant changes occurred in the charred rice residues-rubber tree twigs tablets after their embedding with NPK fertilizer. The absorption band between 1,400.75-1,614.25 $\mathrm{cm}^{-1}$ for aromatic $C$ ring and $\mathrm{C}-\mathrm{O}$ stretching $\left(1,080.16 \mathrm{~cm}^{-1}\right)$

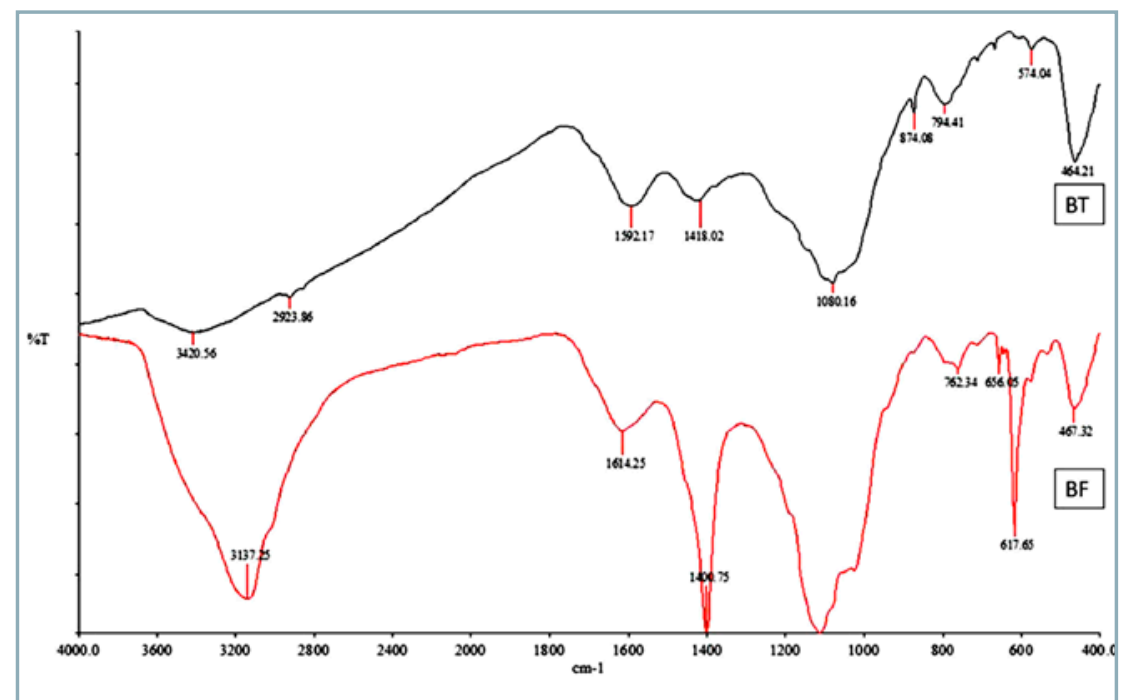

Fig. 1 FTIR spectra of tablets made of charred rice residues-rubber tree twigs mixture embedded with (BFs) and without fertilizer (BTs)

are observed in both BFs and BTs. The presence of aromatic $C$ ring and primary alcohol $\mathrm{C}-\mathrm{O}$ stretching are typical chemical groups of biochar (Armynah et al., 2018). The chars consist of aromatic C compounds that are degraded slowly by microorganisms. The formation of $\mathrm{C}-\mathrm{O}$ stretching indicates that the biomass was partially decomposed during the combustion. These findings are consistent with Leng et al. (2013), who also discovered that the presence of primary alcohol $\mathrm{C}-\mathrm{O}$ stretching in the char was due to the partial oxidation of cellulose in the charring process. This indicates that ability of BFs and BTs to release the nutrients slowly is attributed to the presence of easily degradable aliphatic and oxidized compounds, as well as the aromatic compounds.

Broad absorption at $3,420.56 \mathrm{~cm}^{-1}$ indicates the presence of alcohol and phenolic groups in the charred rice residues and rubber tree twigs mixture pellet. Fig. 1 shows the appearance of $\mathrm{NH}$ stretch $\left(3,137.25 \mathrm{~cm}^{-1}\right)$ in the BFs, suggesting the sorption of ammonium substances to the char. In contrast to BTs, strong stretch occurs at $650 \mathrm{~cm}^{-1}$, suggesting the presence of sulphonic acids in the BFs. This is attributed to higher amount of ammonium sulphate added to the charred rice residues and rubber tree twigs mixture pellet. Phosphorus compounds $\left(1,400.75 \mathrm{~cm}^{-1}\right)$ were also observed in the BFs due to the addition of rock phosphate fertilizer.

\section{Conclusion}

Tableting process increases the densities and durability of BTs and BFs. In terms of quality, higher amount of nutrients in BFs makes it a potential nutrient supplier for plants. The blending of ammonium sulphate fertilizer with the biochar tablets significantly increased the concentration of total N, which is essential element required for successful plant growth, development, and reproduction. Therefore, application of BFs can increase the amount of inorganic nitrogen absorbed by plants. BFs are not only made up of aromatic compounds but they also include easily degradable aliphatic and oxidized C compounds. Therefore, it has the potential to slowly release the nutrients and to serve as a replacement of the inorganic fertilizer. Further investigation is also needed to determine the decomposition rate and nutrient release of biochar with and without embedded fertilizer.

\section{Acknowledgements}

We express our gratitude to Universiti Putra Malaysia, Universiti Malaysia Perlis, and Ministry of Higher Education Malaysia for the continued support in our research work related to biochar through Putra Grant and Fundamental Research Grant Scheme. 


\section{References}

ARMYNAH, B. - ATIKA - DJAFAR, Z. - PIARAH, W. H. - TAHIR, D. 2018 Analysis of chemical and physical properties of biochar from rice husk biomass. In Journal of Physics: Conference Series, vol. 979, no. 012038.

ADAPA, P. K. - SCHOENAU, G. J. - TABIL, L. G. - SOKHANSANJ, S. CRERAR, B. J. 2003. Pelleting of fractionated alfalfa products. In ASABE paper no. 036069, ASABE, St. Joseph, MI.

ANDREASEN, C. - KEMEZYS, A. H. - MULLER, R. 2014. The effect of fertilizer level and foliar-applied calcium on seed production and germination of gerbera hybrid. In HortScience, vol. 49, pp. 538-543. BREWER, C. E. - CHUANG, V. J - MASIELLO, C. A. - GONNERMANN, H. GAO, X. - DUGAN, B. - DRIVER, L. E. - PANZACCHI, P. - ZYGOURAKIS, K. - DAVIES C. A. 2014. New approaches to measuring biochar density and porosity. In Biomass and Bioenergy, vol. 66, pp. 1-10.

CHEN, Y. Q. - TANG, J. J. - LI, W. L - ZHONG, Z. H. - YIN, J. 2015. Thermal decomposition of magnesium ammonium phosphate and adsorption properties of its pyrolysis products toward ammonia nitrogen. In Transactions of Nonferrous Metals Society of China, vol. 25 , pp. 497-503.

CLAOSTEN, N. - SAMSURI, A. W. - AHMAD HUSNI, M. H. - MOHD AMRAN, M. S. 2014. Effects of pyrolysis temperature on the physicochemical properties of empty fruit bunch and rice husk biochars. In Waste Management Research, vol. 32, pp. 331-339.

DEPARTMENT OF STATISTICS MALAYSIA. 2016. Press release: Selected Agricultural Indicators, Malaysia.

DHAUNDIYAL, A. - HANON, M. M. 2018. Calculation of kinetic parameters of the thermal decomposition of residual waste of coniferous species: Cedrus deodara. In Acta Technologica Agriculturae, vol. 21, no. 2, pp. 75-80.

DRÓŻDŻ, T. - KIEŁBASA, P. - KORENKO, M. - NAWARA, P. - PIKUL, K. 2016. High frequency induction tube furnace for determination of ash melting temperature. In Acta Technologica Agriculturae, vol. 19 , no. 4, pp. 84-88.

DUNNIGAN, L. - ASHMAN, P. J. - ZHANG, X. - KWONG, C. W. 2018 Production of biochar from rice husk: Particulate emissions from the combustion of raw pyrolysis volatiles. In Journal of Cleaner Production, vol. 170, pp. 1639-1645.

GONZAGA, M. I. S. - MACKOWIAK, C. L. - COMERFORD, N. B MOLINE, E. F. V. - SHIRLEY, J. P. - GUIMARAES, D. V. 2017. Pyrolysis methods impact biosolids-derived biochar composition, maize growth and nutrition. In Soil and Tillage Research, vol. 165, pp. 59-65.

HUSK, B. - MAJOR, J. 2008. Commercial Scale Agricultural Biochar Field Trial in Quebec, Canada, Over Two Years: Effects of Biochar on Soil Fertility, Biology, Crop Productivity and Quality. Blue Leaf, Quebec, Canada.

JOSEPH, S. - GRABER, E. R. - CHIA, C. - MUNROE, P. - DONNE, S. THOMAS, T. - NIELSEN, S. - MARJO, C. - RUTLIDGE, H. - PAN, G. X. LI, L. - TAYLOR, P. - RAWAL, A. - HOOK, J. 2013. Shifting paradigms: development of high-efficiency biochar fertilizers based on nanostructures and soluble components. In Carbon Management, vol. 4, pp. 323-343.

KARIM, R. S. M. - MAN, A. B. - SAHID, I. B. 2004. Weed problems and their management in rice fields of Malaysia: an overview. In Weed Biology and Management, vol. 4, pp. 177-186.

LENG, L. Y. - AHMAD HUSNI, M. H. - SAMSURI, A. W. 2013. Stability of pineapple leaf residue chars generated by controlled combustion and by field burning in tropical peat. In Clean-Soil Air Water, vol. 41, pp. 1-9.
LENG, L. Y. - AHMAD HUSNI, M. H. A. - SAMSURI, A. W. 2011. Comparison of the carbon-sequestering abilities of pineapple leaf residue chars produced by controlled combustion and by field burning. In Bioresource Technology, vol. 102, pp. 10759-10762.

LIMVIKRAN, T. - KHEORUENROMNE, I. - SUDDHIPRAKARN, A. PRAKONGKEP, N. - GILKES, R. J. 2018. Dissolution of K, Ca, and P from biochar grains in tropical soils. In Geoderma, vol. 312, pp. 139-150. MACÁK, M. - NOZDROVICKÝ, L. - HUSSEIN, A. O. 2015. Effect of preheating and different moisture content of input materials on durability of pellets made from different phytomass content. In Acta Technologica Agriculturae, vol. 18, no. 1, pp. 22-27.

MANDAL, S. - DONNER, E. - VASILEIADIS, S. - SKINNER, W. - SMITH, E. - LOMBI, E. 2018. The effect of biochar feedstock, pyrolysis temperature, and application rate on the reduction of ammonia volatilisation from biochar-amended soil. In Science of the Total Environment, vol. 627, pp. 942-950.

MAJOR, J. - RONDON, M. - MOLINA, D. - RIHA, S. J. - LEHMANN, J. 2010. Maize yield and nutrition during 4 years after biochar application to a Colombian savanna oxisol. In Plant and Soil, vol. 333, pp. 117-128.

O'CONNOR, D. - PENG, T. - LI, G. - WANG, S. - DUAN, L. - MULDER, J. -CORNELISSEN, G. - CHENG, Z. - YANG, S. - HOU, D. 2018. Sulfurmodified rice husk biochar: $A$ green method for the remediation of mercury contaminated soil. In Science of the Total Environment, vol. 621, pp. 819-826.

QIAN, L. - CHEN, L. - JOSEPH, S. - PAN, G. X. - LI, L. Q. - ZHENG, J. W. - ZHANG, X. H. - ZHENG, J. F. - YU, X. Y. - WANG, J. F. 2014. Biochar compound fertilizer as an option to reach high productivity but low carbon intensity in rice agriculture of China. In Carbon Management, vol. 5, pp. 145-154.

RONDON, M. A. - LEHMANN, J. - RAMÍREZ, J. - HURTADO, M. 2007. Biological nitrogen fixation by common beans (Phaseolus vulgaris L.) increases with bio-char additions. In Biology and Fertility of Soils, vol. 43, pp. 699-708.

SHAFIE, S. M. - MASJUKI, H. H. - MAHLIA, T. M. I. 2014. Life cycle assessment of rice straw-based power generation in Malaysia. In Energy, vol. 70, pp. 401-410.

SHENG, Y. Q. - ZHU, L. Z. 2018. Biochar alters microbial community and carbon sequestration potential across different soil $\mathrm{pH}$ In Science of the Total Environment, vol. 622-623, pp. 1391-1399.

SHENG, Y. Q. - ZHAN, Y. - ZHU, L. Z. 2016. Reduced carbon sequestration potential of biochar in acidic soil. In Science of the Total Environment, vol. 572, pp. 129-137.

SINGH, B. - CAMPS-ARBESTAIN, M. - LEHMANN, J. 2017. Biochar: A Guide to Analytical Methods. In CSIRO Publishing, pp. 1-320.

VAUGHN, S. F. - KENAR, J. A. - THOMPSON, A. R. - PETERSON, S. C. 2013. Comparison of biochars derived from wood pellets and pelletized wheat straw as replacements for peat in potting substrates. In Industrial Crops and Products, vol. 51, pp. 437-443.

WEBER, K. - QUICKER, P. 2018. Properties of biochar. In Fuel, vol. 217, pp. 240-261.

XUE, B. - HUANG, H. - MAO, M. - LIU, E. 2017. An investigation of the effect of ammonium sulfate addition on compound fertilizer granulation. In Particuology, vol. 31, pp. 54-58.

YI, S. - GAO, B. - SUN, Y. - WU, J. - SHI, X. - WU, B. - HU, X. 2016. Removal of levofloxacin from aqueous solution using rice-husk and wood-chip biochars. In Chemosphere, vol. 150, pp. 694-701. 